\title{
Formation of the Motivational-valuable Relation to the Physical Culture in Students in the Social-cultural Environment of the Higher Educational Establishment
}

\author{
Daniel Paskalyevich Adeyemi
}

Ural Federal University

Email: danrim@mail.ru

\author{
Doi:10.5901/mjss.2015.v6n1s2p109
}

\begin{abstract}
The article discusses theoretical and practical questions of motivational-valuable attitude formation toward the physical culture in students. The didactic approach of purpose formation on the physical-recreational activity, process of fixing the new behavioural scheme in the modern social-cultural environment of the higher educational establishment was represented.
\end{abstract}

Keywords: physical culture of personality, social-cultural environment, social-culture activity, motivational-valuable relation to physical culture.

\section{Introduction}

Presently the new type of social development of the society generates the new type of citizens. In the competitive conditions the energetic, socially adapted and active person survives. Maximization of the own conditions of the population is inseparably connected with the exercises of physical culture, providing the psychophysical potential, necessary for preservation of the health and labour capacity.

The demand in the physical culture is main stimulating means, directed and regulating the force of personality behaviour, which have the wide spectre: demand in movement and physical loading, in communication, contacts and spending the free time in the circle of friends, games, entertainments, rest, emotional discharge, self-assertion, and strengthening of the positions of own "Ego", in cognition, aesthetic pleasure, improvement of the quality of physic-cultural sport trainings (Shapkova, 2009).

The task of the attraction of the students to the values of physical culture requires the creation of the general system of education in the area of physical culture in the professional educational institutions. Presently the level of physical preparedness and state of health of the youth who study does not satisfy the demands of the society. At that it is necessary to understand clearly that it doesn't go about the increase of efficiency of an individual in future professional activity, and physical improvement as one of the aims of upbringing of the personality and increase of its culture. It once more shows that the very physical culture doesn't exist separately from the culture on the whole.

At understanding the natural and social determination of physical culture of personality the general pedagogical and psychological approaches, issues related to the personality socialization, and moving forces of its development, creativity and activity are accepted. In the range of modern sources more than one determination of the physical culture of personality exist, where each one considers this determination from the certain corner. However, the general sign for all notions is the acquisition of the fact that the essence of physical culture of personality lies in self-realization of a human, in the development of own personal and physical abilities, acquisition of values of physical culture on the basis of unity and positive interrelation of biological and social in a human, material (moving) and spiritual (intellectual) one (Davydov, 2008).

\section{Methods}

One of the main health saving factors is acknowledged as physical culture of a personality on the whole. However, frequently the generally developed role of physical culture is reduced only to the refractive environment and sees in it only the improvement of physical constituent of the health, and spiritual-moral and social-psychological part of the health phenomenon are given on formation and development of the spheres of education system. However at physical culture characteristics it is necessary to take into account three of its aspects - active, subjective-valuable and personifiedeffective that finally shows closeness of notions of the physical culture and healthy way of life, as in this case the point is 
going about social phenomena, relating to the psychophysical development, recovery, and human improvement (Malozemov, 2007).

The physical culture trainings have peculiar significance for student youth as the special social-cultural community, representing the human potential of the productive layers of society.

From culturological positions formation of the physical culture of students is acquisition of the public values of physical culture (material and spiritual), i.e. their transformation into personal values. Among culturological conceptions the leading ones are as follows: 1) substantiation of the theoretical-methodological bases of physical culture activity (physical culture education, physical recreation, sport and etc.); 2) unity of intellectual, social-psychological and moving component in the process of physical culture formation of personality; 3 ) understanding of the human essence in the unity of motivational-demanding, active, effective, personal relation to the values of physical culture; 4) integrative function of the physical exercises as elements of physical culture activity connected not only with the motility of a human, but with its spiritual development, formation of the cognitive, emotional, physic, sense, evaluation activity, i.e. entering into physicalspiritual unity; 5) age evolution of human motility and adequate stimulation of moving functions in the different periods of life; 6) physical culture of personality as a constituent part of the healthy way of life, physical, psychic, and social health. Basically, absolutely all these conceptions represent the methodological foundation of the physical culture (Kobelev, 2008).

From the positions of methodological approach the development in the process of different types of activity in the physical culture area, directed on their physical improvement, are recognized as the basic means of personal physical culture formation of the students of higher educational establishments. Such approach to understanding of the physical culture essence, when the interrelation of the intellectual, social-psychological and moving components is the basic aim, allows not only to evaluate problems of physical culture formation of the student, but also bring the necessity of physical culture and sport exercising to the consciousness of the students (Balsevich, Vilenskii, Vydrin, Kombachkov etc.) (Malozemov, Kovalevskii, Prokopenko, 2007).

At realization of such aim of study, formation in the students of the motivational-valuable relation to physical culture and purpose for healthy way of life, physical improvement and self-education, demand in the regular physical exercise and sport trainings as to social phenomenon can be considered the top priority task. Thus, the demanding-motivational area is system-forming factor of all educational effects and is formed in the process of social-psychological, intellectual and moving (physical) education.

At entrance into higher education establishment the student is forced to adapt himself to the complex of new factors, specific for the higher educational establishments. Such adaptation represents the complex multi-level socialphysical process and is accompanied by the substantial tension of compensatory-adaptive systems of students' organism. In order that the adaptation take place more successfully, the peculiar methods of exercise conduction on the students' physical education that will allow cultivation of the demand in physical culture and, as a result, regulation of the students' behavioural change (Vydrin, 1991).

The very model of behaviour change includes several stages into it (Martsinkovskaya, 1998).

- premeditation: student doesn't acknowledge the presence of problem, and is not ready to changes;

- purpose (beginning of changes): weighting of all "pros" and "cons", and understanding of the contradictions;

- solution: is accepted in relation to whether change the current behaviour or no;

- action: realization of the solution in practice, concrete actions;

- support: active support, confirmation of the changes by personality, reaction of the teacher and group;

- relapse: more or less prolonged and serious return to the primary behaviour;

This model is cyclic one, and each student can leave it on any stage. The stage, where student locates, is the basic indicator of the possible progress: the farther he moved by "spiral of changes", the more appearance of positive results is possible.

We'll mark that the methods of conducting the exercises on regulation of behavioural changes was based on the following principles:

- the educational process is oriented on the general development of personality of a students, divergence of his thought;

- educational process touches not only motivational-valuable structure of personality, but also forms socially meaningful personal qualities;

- the usage of personally oriented technologies and purposes in the educational process, which essence is reduced to that the student must learn to transform the quality of physical culture recreational activity in such a way that it would become the effective means of self-development of its essence, intellect, and creative 
energy;

- the model of behaviour change, developed by the American physiotherapist Prochaska and DiClemente, based upon which it is possible to build the most optimal way of solution of the problem or conflict situation or choice situation.

On the classes the student teaches to manage the physic processes, emotions and feelings. Owing to settlement of the tasks, which should be executed, the student must build the most optimal way of situation solution. During the time of study in school the situations, in which the deliberate choice of way for problem overcoming, are put before the students. The task of higher educational establishment is creation of such social-cultural environment that owns the free choice. Such freedom is necessary to a student only in order to provide the social and professional personality environment, able at necessity to change profession quickly, develop the new social roles and functions, and be competitive able.

At realization of these principles of building exercises in student the motivational-valuable relation to physical culture is formed. It is necessary to separate several motives, which lead to change of a student's behaviour:

- problem understanding: a student understands the presence of problem and significance of the information obtained that creates preconditions of acceptance of effective solutions for deciding the tasks set;

- self-overestimation: on the emotional and rational level the advantages and disadvantages of behavioural change are evaluated. For example, a student compares consequences from non-accomplishment of the task or non-attendance of the training as discharge of own personal time and possibility not to load physically on the one part, and as a real threat to receive "not pass" on the subject and worsen the state of own health, on the other part;

- personal and social discharge: focusing on the negative consequences for people around, isolation from the group that attends the classes, appearance of own views on life, and faith into personal abilities;

It should be noted that the process of motivation formation includes several stages:

- creation of confidence in himself;

- obtainment of the necessary information;

- appearance of the competence feeling;

- appearance of understanding of the necessary changes.

In the process of formation of motivational-valuable relation of students to physical culture, successful execution of activity, including any physical-recreational one on the classes is provided for personality with technological stability at preservation of the realization vector direction. The similar readiness to act correspondingly is expressed in the notion "purpose" that serves as stabilizer and regulator of any student's activity.

The purpose is created in the process of student's experience, and serves as orientation on the activity object; readiness, "personal reality" is the state of subject, its modus, and process of fixing on his new scheme of behaviour. The purpose can:

- determine the stable, consecutive, and purposeful character of flowing the student's activity and serve as a mechanism of its stabilization, which allow preservation of its direction into uninterruptedly changed situations;

- discharge student from the necessity to take decisions and randomly control activity operation in the standard earlier met situation.

Any purpose for a student on the classes is lead through persuasion that is the basic method of effect. Persuasion as a method in pedagogy is optimal for personal-oriented study as:

- based on the subject-subjective type of communicative effect in the "student-student" system;

- suppose ability of a teacher to stand on a student's position, analyze the peculiarities of actual speech situation and act with word taking into account these and many other factors flexibly, adequately to situation, and in recipient-oriented manner;

- allow creatively generate and use maximally effective forms and means of speech effect between teacher and student (Ushinskii, 1948-1952).

With the aim of effectiveness of physical culture trainings on behavioural changes the experimental-search work with first-year students of Ural State University named after A. M. Gorky was conducted. We analyzed the indicators of attendance and advancement rate of students on the discipline of physical culture for different faculties.

We suppose that the state of health is the basic indicator of changes, which take place with students at physical culture exercises.

The analysis of the students' medical examination results shows that at entrance $60 \%$ students have the basic medical group, and the students are distributed almost equally (21\% and $19 \%$ respectively) into preparatory and special 
medical group.

The study detected that at systemic physical culture exercises during 2 semesters the indicators of student's health are improved (Table 1).

Table 1. Monitoring of students' health in 1 and 2 semester

\begin{tabular}{|c|c|c|c|}
\hline Medicinal group & 1 semester & 2 semester & $\Delta$ (diversity of indicators) \\
\hline Basic & $60 \%$ & $75 \%$ & $15 \%$ \\
\hline Preparatory & $21 \%$ & $16 \%$ & $-9 \%$ \\
\hline Special & $19 \%$ & $9 \%$ & $-10 \%$ \\
\hline
\end{tabular}

Thus, the quantity of students, which at the beginning of study in higher educational establishment have special and preparatory medicinal groups of health was reduced on $10 \%$ and $5 \%$ (and made $9 \%$ and $16 \%$ respectively), while the quantity of students, which have basic medicinal group, increased for $15 \%$ and made $75 \%$.

Based upon study results on the demand of students' physical culture students, it is necessary to note that one of the signs of motivational-valuable purpose formation on the physical-cultural activity is the necessity of attendance on compulsory physical exercise trainings. Thus, attendance of the classes by students during the semester is satisfaction of the demand in the physical culture exercises, as well as communication with those of similar age, but not the compulsory condition of pass obtainment on the discipline.

The analysis of attendance of the classes by students show that maximal inter-semester growth of attendance during the first year of study in students of 2012 year of entrance and makes 7\%, and improvement of the classes attendance makes 2-3\% in students, who entered in 2013 (Table 2).

Table 2. Monitoring of classes attendance by the students

\begin{tabular}{|c|c|c|c|c|c|c|}
\hline \multirow{2}{*}{ Entrance year } & \multicolumn{2}{|c|}{2012} & \multicolumn{2}{c|}{2013} & \multicolumn{2}{c|}{ (diversity of indicators) } \\
\cline { 2 - 7 } & 1 semester & 2 semester & 1 semester & 2 semester & 2009 e.y. & 2010 e.y. \\
\hline Faculty & $72 \%$ & $75 \%$ & $73 \%$ & $80 \%$ & $3 \%$ & $7 \%$ \\
\hline International relations & $70 \%$ & $72 \%$ & $71 \%$ & $77 \%$ & $2 \%$ & $6 \%$ \\
\hline Biological & $66 \%$ & $68 \%$ & $65 \%$ & $66 \%$ & $2 \%$ & $1 \%$ \\
\hline Public relations and advertisement
\end{tabular}

The data of table allow us concluding that constantly the formation of purpose on valuable relation to own health by means of physical culture and recreational activity takes places, as well as the development of physical culture on the whole.

The complex physical training of the students in the university is evaluated by the range of standards and texts (8 parameters on the scale from 0 to 5 each). The results of testing allow us determining the level of student's physical training (Table 3).

Table 3. Monitoring of the physical training level

\begin{tabular}{|c|c|c|}
\hline Semester & Average quantity of points in the group & $\Delta$ (diversity of indicators) \\
\hline 1 & 24.7 & - \\
\hline 2 & 32.5 & 7.8 \\
\hline
\end{tabular}

\section{Results}

Based upon the data obtained in the course of experimental-search work, it is possible to conclude that the powerful growth of advancement and physical preparedness of students is observed to ending the second semester of study that it is explained by the presence of average level of motivational-valuable purpose formation on the physical-recreational activity at physical culture exercises. This level evidences about primary social-practical and applied experience that the student acquires, readiness to mastering and usage in his activity of the self-knowledge methods, correction of behaviour and reflection. 


\section{References}

Astafyev, V. S. (2009). Theoretical aspects of physical culture formation of HEl students' personality. Theory and practice of physical culture, 8.

Davydov, O. Yu. (2008). Athletic gymnastic - the universal means of improvement of the general physical preparedness of students of technical higher education establishment. Theory and practice of physical culture, 8.

Kobelev, Ya. S., Umrikhrin, Yu. A. (2008). Formation of personality physical culture with usage of computer technologies. Theory and practice of physical culture, 3 .

Malozemov, O. Yu., Kovalevskii, A. K., Prokopenko, V. I. (2007). Physical culture as integrating factor of students' health saving. Yekaterinburg: Publ. house AMB.

Martsinkovskaya, T. D. (1998). The history of psychology: text-book for students of the pedagogical universities. Moscow: VLADOS.

Mukhamitianov, F. D. (2008). Physical culture as social phenomenon and cultural phenomenon. Theory and practice of physical culture, 9.

Shapkova, L. V. (2009). Culturological constituent of the adaptive physical culture. Theory and practice of physical culture, 12.

Shinkorenko, O. V., Logunov, V. I. (2008). Basic direction of demand formation in the systemic physical training classes in students of the technical university. Theory and practice of physical culture, 6 .

Theory and methods of physical culture: text-book. (2003). Edited by Kuramshina, Yu. F. - Moscow: Soviet sport.

Ushinskii, K. D. (1948-1952). Labour in its psychic and educational meaning. Moscow: Pravda.

Vilenskii, M. Ya. (2001). Basis substantial characteristics of pedagogical technology of personality physical culture formation. Physical culture: upbringing, education, and training, 3.

Vydrin, V. M. (1991). Physical culture of the students of higher educational establishments. Voronezh: Education. 